\title{
Neuroemulation: definition and key benefits for water resources research
}

Robert J. Abrahart

School of Geography, University of Nottingham, Nottingham, NG7 2RD, UK

Tel: +44115846 6145 Fax: + 441159515249

Email: bob.abrahart@nottingham.ac.uk

Nick J. Mount

School of Geography, University of Nottingham, Nottingham, NG7 2RD, UK

Tel: +441159515438 Fax: + 441159515249

Email: nick.mount@nottingham.ac.uk

Asaad Y. Shamseldin

Department of Civil and Environmental Engineering, University of Auckland, Private Bag 92019, Auckland, NZ

Tel: +64 93737999 ext 88499 Fax: +64 93737462

Email: a.shamseldin@auckland.ac.nz

\begin{abstract}
Neuroemulation is the art and science of using a neural network model to replicate the external behaviour of some other model and it is an activity that is distinct from neuralnetwork-based simulation. Whilst is has become a recognised and established subdiscipline in many fields of study, it remains poorly defined in the field of water resources and its many potential benefits have not been adequately recognised to date. One reason for the lack of recognition of the field is the difficulty in identifying, collating and synthesising published neuro-emulation studies because simple database searching fails to identifying papers concerned with a field of study for which an agreed conceptual and terminological framework does not yet exist. Therefore, in this paper we provide a first attempt at defining this framework for use in water resources. We identify eight key benefits offered by neuro-emulation and exemplify these with relevant examples from the literature. The concluding section highlights a number of strategic research directions, related to the identified potential of neuroemulators in water resources modelling.
\end{abstract}

\section{INTRODUCTION}

Increasing awareness and adoption of emulators for performing water resources research, spurred on by associated developments in computer power and data-driven modelling, is causing a minor methodological revolution in the way things are modelled. The emulator is an auxiliary model which does not explicitly attempt to model the internal state conditions of a process-related physically-based model: an emulator only attempts to reproduce the latter's external output(s). In a strict sense, model $X$ is said to emulate another model, $Y$, if the external behaviour (response function) of $X$ under similar conditions is approximately the same as that of $Y$, albeit that the mechanism which is being used to deliver a set of near-identical answers is different i.e. the same input produces the same output but not for the same reason. Emulation is distinct from simulation, which occurs at a higher level, and for which the aim is to develop internal mechanisms or procedures which represent real-world phenomena in some meaningful way.

Emulation is said to deliver numerous advantages (Friedman \& Pressman, 1988) which include enhanced modelling efficiency; enhanced model elegance and simplification; opportunities for improved model exploration and interpretation; model generalisation to other models of the same type; sensitivity analysis; model optimisation; answering 
inverse questions and providing the researcher with a better understanding of the behaviour of both the system under study and the interrelationships among its variables.

Emulators can be developed for a number of different reasons. However, since their overall goal is to imitate the operational output of another model, it is theoretically possible to develop and implement:

- full emulation, using a complete set of original model inputs (i.e. identical drivers); or

- partial emulation, using a subset of original model inputs: by omitting certain predictors, for example, if standard input drivers are not immediately available, or cannot be accessed, or for model reduction purposes; or

- augmented emulation, using a mixed combination of original and additional model inputs, such as 'tangential' or 'contextual' variables' i.e. information reflecting physical insight into a problem, or particulars relating to global properties of the original dataset e.g. parametric information describing some overall structural aspect or pertaining to certain specific features of a particular dataset

- surrogated emulation, using a totally different set of model input drivers, to deliver identical and/or modified original model outputs.

Emulators can also be developed to fulfil the role of independent standalone applications and/or used as an integrated component as part of some larger system. The fundamental issue at stake is that the emulator must be reproducing some aspect of the original model.

Emulation commonly applies either a traditional/statistical black-box approach (e.g. Reichert et al., 2011) or, more recently uses neural network models (NN). It has become an established element of modelling activities in many fields such as industrial processing (e.g. Swingler, 1996), where NN emulators are called 'neuroemulators'; the art and science of constructing a neuroemulator is termed 'neuroemulation'; and the established use of neuroemulator applications for modelling or controlling dynamic systems is widely acknowledged. Neuroemulation is also a recognised subset of neurohydrid modelling: for a discussion on other types of neuro-hybrid solution, see Van den Boogaard \& Kruisbrink (1996) and Abrahart et al. (submitted). However, in water resources, the establishment of neuro-emulation as an activity distinct from NN-based simulation has not been so forthcoming. Indeed, hundreds of papers concerned with hydrological simulation using NNs can easily be identified using standard database searches (for example, Ahmad and Simonovic, 2005; Dawson et al., 2006; Wu et al., 2009). The same can not be said for neuro-emulation. This is because the framework of a clear conceptual definition and terminology which distinguishes neuro-emulation from other NN modelling activities in water resources is as yet not adequately established. This makes it extremely difficult to disentangle neuro-emulation papers from those concerned primarily with simulation. It is not so much that hydrological neuro-emulation is not being done, but that it is not being fully differentiated by those doing it, and this means that its specific benefits for water resource studies are not being adequately recognised. Indeed, the challenge in establishing neuro-emulation as a distinct hydrological sub-discipline that is able to demonstrate its specific scientific and practical benefits to the water resource modeller requires three core steps to be undertaken:

1. The conceptual and terminological definition of the sub-discipline and its positioning within the context of broader water resources modelling activities so that it can be properly distinguished from them;

2. The identification of its benefits, as exemplified from existing studies in which emulation has been a central component; 
3. The highlighting of research directions for which hydrological emulation offers clear potential; thereby encouraging others to pursue it and providing forward traction for future studies to further develop the emerging sub-discipline.

This paper addresses these three core steps by formalising the conceptual definition and terminology surrounding emulation, providing a classification of the benefits of neuroemulation in water resources as evidenced and exemplified from published literature, and suggesting a range of future research directions that offer potential benefits.

\subsection{Terminology}

The conceptual definition and terminology surrounding emulation is clearly of importance, but can often be confusing or ambiguous. Terms such as emulator, metamodel, compact model, response surface, surrogate or proxy are often applied in an interchangeable manner or, in certain cases, some penchant is expressed for one or other descriptor in a particular scientific discipline according to impulse or following an earlier precedent. The meta-model descriptor is of particular concern since it is frequently used to represent a diverse set of fundamentally different scientific entities, spread across various modelling domains. For example:

- a categorisation of theoretical models according to their quantitative or formal properties (Slobodkin, 1958; cited in Chorley \& Haggett, 1967).

- a model of a numerical model (Blanning, 1975; cited in Broad et al., 2005)

- a model of a physical laboratory model e.g. flume experiment (e.g. Kumar et al., 2010).

- a minimum information requirement lower-order model of the simplest structure, that satisfies the modelling needs of some driving interest, whilst still ensuring that the model parameters retain their physical significance (e.g. Quinn, 2004).

- a higher-level abstraction or description of an individual model - highlighting certain specific properties of that original model e.g. the explicit framework of rules, logic and reasoning which underpin it.

Consequently, a general tightening of meaning or so-called controlled vocabulary of nomenclature for hydrological modelling emulator science is required i.e. a list of terms which have been enumerated explicitly. All terms in a controlled vocabulary should have an unambiguous, non-redundant definition and, at a minimum, the following two rules should be enforced:

1. If the same term is commonly used to mean different concepts in different contexts, its name should be explicitly qualified to resolve this ambiguity.

2. If multiple terms are used to mean the same thing, one of the terms should be identified as the preferred term, and other terms listed as synonyms or aliases.

Figure 1 proposes a scheme for such a vocabulary based on a rationalisation of existing modelling nomenclature used in water resources research. The emulator is situated in a basic hierarchy comprising real world, meta-model, functional model and emulator. Importantly, in our hierarchy a meta-model is a higher-order generalisation of the real world. It documents a conceptual blueprint, to which some larger set of functional models will conform, in the same way that a computer program conforms to the grammar of the programming language in which it is written. This interpretation is consistent with other meta- prefix labellings in different subject domains and as such a meta-model abstraction is not a functional model. It cannot be used to deliver predicted output. Emulation is completely distinct from the meta-model and it functions at the lowest conceptual order. Emulators are substantially more removed from real world 
physical processes, compared to a functional model simulator, and do not implicitly attempt to provide a degraded realisation of 'process'. They pay no real attention to the underlying mechanics but are instead simply designed to deliver full probabilistic predictions of the original simulator output. Each emulator should also be capable of predicting simulator output to any level of desired accuracy.

\subsection{Methodology}

The identification of water resources papers in which neuro-emulation features is particularly problematic. Standard contemporary approaches based on literature database queries can only ever uncover papers that have been indexed to an established and accepted taxonomy of disciplines and the sub-disciplines / activities that exist within them. At present, neuro-emulation is an emerging field that has yet to be widely recognised as a distinct activity by those concerned with water resource studies. Thus the terminology surrounding neuro-emulation does not feature within the taxonomic structure to which these studies are indexed and its explicit identification within the title, abstract and key words of papers is uncommon. Indeed, the present lack of a conceptual and terminological definition makes it difficult to identify the search terms best placed to identify neuro-emulation papers in a database query of water resource literature. The historical record of such activities is, as a result, very difficult to uncover since papers which have deployed neuroemulators are hard to detect. This prohibits the production of a definitive list of all relevant neuroemulation papers in water resources research via standard searches.

For example, a systematic search for relevant papers on water resources issues was performed using the Thomson Reuters (formerly ISI) Web of Knowledge research platform [19 July 2011]:

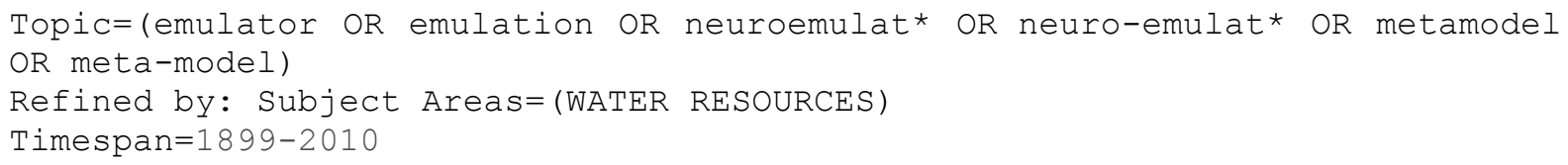

This query returned only 38 papers, with a total citation count of 259, for the period 1992 to 2010 (Figure 2). Metamodel was the most 'popular term'. Neuroemulat*/Neuroemulat* did not identify any papers. Importantly, most papers which apply emulation and neuroemulation in water resources research, and which were collected by the authors in an ad hoc manner over the course of several years of general research into the wider application of NN for hydroinformatics, were not identified.

The alternative to database searching is the adoption of a more traditional approach to uncovering relevant literature that places the emphasises on the ability of those seeking the literature to adequately synthesise and collate it. Indeed, in seeking to define new or emerging areas of study, the use of researchers' experience and contextual knowledge of a wide body of potentially-relevant literature is arguably an appropriate way to proceed. This is because it allows the flexible re-interpretation of the conceptual underpinnings, semantics and terminology detailed in each study to a new framework defining the emergent sub-discipline. This is an essentially qualitative process founded on a high-level abstraction and it can not be duplicated by simple Boolean search operations. The method used to identify papers for inclusion in this review follows this approach, and draws upon the authors' own collections of several hundred papers, spanning the last two decades, in which data-driven modelling in general, and NN modelling in particular, are applied in water resource studies. The case studies are selected by the authors primarily for their illustrative value as exemplars of particular modelling opportunities/ benefits. Further, in most sections, the selected papers also represent the first recorded pioneering application(s) on a particular topic or issue of interest. It is, however, accepted that the discovery of additional neuroemulation 
publications may shed more light on the issues which are discussed in the manuscript, and potentially suggest new or amended categories of neuroemulator applications.

The remaining sections of this paper are devoted to delivering an overview of potential applications of neuroemulation for different aspects of water resources research. The review is organised according to a structured categorisation of eight key benefits; developed iteratively. Each category includes example case studies; assigned according to the principal reason for developing a neuroemulator as stated in each paper.

\section{NEUROEMULATION APPLICATIONS IN WATER RESOURCE RESEARCH}

Traditionally, the use of emulators in water resources research, has comprised a response to objectives situated on a continuum ranging between operational and scientific. If the emphasis was placed on operational deliverables, the objective is to develop models that are more efficient in terms of computational speed and/or data requirements. For example, Bond et al. (1979) developed a simple parametric inputoutput emulator to predict the simulated output response obtained using a complex physically-based catchment model. More recently, Reichert et al. (2011) approximated the dynamics of an original hydrological model as a function of both model inputs and model parameters using a simplified linear state model emulator. If the emphasis was placed on scientific deliverables, the objective is to support knowledge acquisition, such as an improved understanding about the functioning of a particular model and its ability to adequately replicate processes in the domain of interest. For example, Rosso (1984), Chuta \& Dooge (1990) and Shamseldin \& Nash (1998) emulated a complex geomorphologically based network of linear reservoirs using the 'Gamma Distribution Instantaneous Unit Hydrograph Model' (Nash, 1957).

Similarly, the scope and purpose of neuroemulator applications can be mapped against such a continuum. In Figure 3 we position our iteratively-developed categories along this continuum, according to the extent to which the reported objectives of each type of study is considered to be either more or less scientific. This ordering then forms the basis for a structural organisation of our eight subsequent sections.

\section{i. Supporting proof of concept}

Neuroemulation can be used to support NN activities by demonstrating proof-of-concept modelling capabilities in a simplified and regulated experimental test bed environment. Novel methods and approaches are put on trial under controlled conditions provided by the original model. The sole purpose of the original model in such cases is to deliver comprehensive datasets of an exact relationship which are easier to model i.e. containing smooth, free-of-noise self-consistent relationships. The end product will nevertheless deliver inflated levels of performance e.g. in modelling pan evaporation, due to the acquisition and prediction of equation-generated outputs, in contrast to observed records, with the latter anticipated to yield a substantially weaker solution which delivered greater errors (Moreno et al., 2010). This category is illustrated by means of specially selected case studies which soundly demonstrate the potential merit of neuroemulation for proof of concept explorations. The neuroemulators in such cases aimed to reproduce predicted model outputs obtained from a set of complex mathematical procedures, but used substantially different input drivers from those which the original modelling mechanisms required.

French et al. (1992) neuroemulated predicted spatial and temporal rainfall outputs originating from a mathematical simulator. Their approach was considered advantageous since it is not subject to data quality and observational error issues, and an essentially unlimited set of records could be generated. The stochastic rainfall model, developed by Rodriguez-Iturbe \& Eagleson (1987), and modified by Krajewski \& Rodriguez-Iturbe (1990), was utilised to construct simulated patterns which served as 'true rainfall'. This 
model conceptualises rainfall as a spatially random Poisson process in which summed contributions of 'rainfall cells' over spatial and temporal domains produces realistic looking rainfall fields. The cells are characterised by their attributes e.g. time of birth, location of birth, rainfall intensity at the centre, velocity, etc. The model, although an obvious simplification of reality, was considered sufficiently complex to provide a sound case study. The simulation domain was $100 \mathrm{~km} \mathrm{x} 100 \mathrm{~km}$ at a resolution of $4 \mathrm{~km}$, yielding a regular grid of $25 \times 25$ points ( 625 points). NN inputs comprised spatially distributed rainfall intensity records: output was forecast intensity valid 1 hour ahead over the same region. The simulation model was used to generate 75 statistically independent events, using identical parameters, such that the statistical characteristics of any sample of events was expected to be preserved. NN performance was compared against persistence and nowcasting approaches. The NN was found to be capable of learning the complex relationship describing the space-time evolution of rainfall, such as that inherent in a complex rainfall simulation model.

Minns \& Hall (1996) neuroemulated predicted discharge outputs originating from a wellestablished conceptual model: RunOff Routing B (RORB: Mein et al., 1974). Their experiments were designed to assess the extent to which such approaches could capture the rainfall and runoff relationship. Their methodology was designed solely to assess the learning capability of a NN. Theoretical catchments were used to investigate a range of different hydrological behaviours, varying from linear to highly nonlinear, all other factors being regarded as equal. Important controls are difficult to isolate and/or asses on real datasets since: (i) it would require prior classification of river regimes as linear or nonlinear; and (ii) influential catchment characteristics will never be exactly equal. RORB itself is a general runoff and streamflow routing program. It is used to calculate flood hydrographs, by subtracting losses from rainfall, to produce rainfall-excess and routing that result through catchment storage to deliver its output. The program settings for their hypothetical catchment equated to a rural drainage area of about $30 \mathrm{~km} 2$ in southern England. For simplicity, no losses were separated and the catchment was considered to have no impervious area. Monte Carlo methods, involving parametric assumptions, were used to construct six storm sequences. Events of varying duration, total depth and profile, occurring at irregular intervals, produced corresponding streamflow outputs. For simplicity, these rainfalls were treated as areal averages. NN were found to be capable of identifying usable relationships between discharges and antecedent rainfalls. It was also suggested that great caution should be applied in studies involving extreme flood events.

\section{ii. Enabling structural diagnostics}

Neuroemulation, by definition, is intended to replicate the external behaviour of selected models. However, from a scientific viewpoint, it is also instructive to compare and contrast the internal structures and/or processing mechanisms arising, with potential counterparts located inside the source model. The modeller could thereby establish the extent of functional similarities and differences and in so doing ascertain if the emulator is: (i) modelling matters in a comparable manner for the purposes of providing additional credibility to the emulator; or, conversely, (ii) providing alternative answers which could be suggestive of conceptual improvements that might be applied to the original functional model or higher level meta-model. Moreover, by means of such extended investigation and reporting, it should be possible to obtain a better understanding of internal neuroemulator dynamics which will in turn assist the neuroemulation community in developing improved solutions.

Wilby et al. (2003) neuroemulated predicted discharge outputs originating from a parsimonious conceptual water balance model (CWBM: Greenfield, 1984; Wilby et al., 1994) of the Test River Basin, in Hampshire, England. Their diagnostic experiments were designed to move away from the concept of using individual NN connection weights, as a basis for analysis, and instead consider hidden units (i.e. an organised collection of 
weights) as the principal means of establishing 'acquired knowledge'. The overall intention was to match/pair hidden units against conceptual model components and thereafter use equivalent functionality to argue a case for analogous representation of physical processes. CWBM daily flows at the basin outlet were simulated using daily estimates of total precipitation and potential evaporation. NN counterparts were developed on different selections of seven potential inputs chosen on the basis of their explanatory power. This included elements of high-frequency forcing, lagged forcing and smoothed forcing. Three experiments were conducted in which the number of inputs upon which the emulators were developed was progressively reduced, so as to determine the extent to which a model could represent hydrological processes using degraded collections of information. The relative impact of each hidden processing unit was examined by means of partial outputs and parallel plots. Their experiments showed that for a three hidden-unit-model, provided with antecedent precipitation and evaporation inputs, outputs associated with two of the hidden units were suggestive of 'baseflow' and 'quickflow' components. The third hidden unit appeared to map important seasonal variations in the soil moisture deficit and exhibited threshold behaviour.

Abrahart \& See (2007) neuroemulated predicted discharge outputs originating from the Xinanjiang Rainfall-Runoff Model (XRRM: Zhao et al., 1980; Zhao, 1992). Their diagnostic experiments were designed to identify the non-linear nature of different functional response surfaces being captured by the NN. The analysis spanned a modest range of rainfall events and catchment conditions, using a constrained random sampling methodology. XRRM was originally intended for use in humid and semi-humid regions. It has a small number of parameters, its structure and components have strong physical meaning, and these factors in combination make it a popular tool for hydrological modelling purposes. The model in the reported paper was formulated as a single equation containing four variables ( 3 inputs and 1 parameter) and no temporal component. The use of random inputs, possessing a uniform distribution, meant that certain unlikely combinations could occur. Full emulations were initially developed using the original model inputs and one of two different outputs: original computed discharge and a calculated runoff coefficient. Partial emulations were also developed on a smaller number of input variables, using omission and conflation of the original inputs, to reveal the changing nature of particular response surfaces which the authors considered to be of hydrological interest. The use of different input combinations also enabled the competencies of neural solutions developed on a reduced number of variables to be assessed. Their visual depictions provided indisputable evidence of reliable non-linear inputoutput mappings being performed, confirming that given a respectable dataset, neural computing can deliver what is required.

\section{iii. Performing sensitivity and uncertainty analysis}

Neuroemulation can be used to examine internal sensitivity and uncertainty in the source model, by means of performing a great number of repeat runs, each based on a series of modified inputs or different parameter sets. The results of such explorations are subsequently used for generating statistical population distributions and in setting confidence limits on the original model. This method of analysis is identical to that used for traditional modelling applications, albeit that the neuroemulator is very much quicker. It is also possible, however, to build a NN model of error surface parameters derived from the source model. Their flexibility and adaptability with regard to inputs and outputs can be employed to deliver sound estimations of several different error quantiles and, by analogy, the shape of probability distributions at each individual point in a forecast.

Shrestha et al. (2009) neuroemulated parameter uncertainty bounds originating from a simplified version of HBV. Instead of building a NN model of the error in process model output, as in standard error updating, a predictive model of parameters describing an error distribution was developed. This is a useful activity, since direct estimation of 
model uncertainty bounds could remove the need to perform a Monte Carlo simulation on real-time applications. It would be especially advantageous if a large number of model runs was not practical, for example in the case of applying complex hydrological models, or if the forecast lead time was very short. Testing was performed on the Brue catchment in South West England. Nine parameters were involved: using ranges based on calibrations derived from other model applications and/or hydrological descriptions of the catchment, extended as necessary, if potential solutions occurred near a border. Monte Carlo simulation was performed on random parameterisations, sampled from nine uniform distributions. HBV is run on each set and a likelihood rejection filter applied. The remainder are used to produce a distribution of potential realisations at each time step: such that calculated upper and lower quantiles can be used to provide an output predictand in the form of either an upper or a lower prediction interval i.e. 'synthetic uncertainty descriptors'. The inputs were standard NN inputs: comprising selected lagged or differenced discharge and effective rainfall records. This method can be extended to predict several different quantiles and by analogy the shape of probability distributions.

\section{iv. Facilitating scenario analysis and decision making}

Neuroemulation is often used to substantially increase the processing speed of an existing application; but, commensurate with such improvements, the very nature and scale of what can actually be achieved within an acceptable waiting period is also changed. High-speed modelling and faster completion times will permit more demanding types of problem to be addressed over realistic periods of computer calculation: (i) by reducing the computational burden involved in resolving convoluted multifaceted planning and design issues arising from scenario analysis; (ii) by enabling 'number crunching' to be replaced with 'model crunching'; and (iii) by supporting the implementation of extended runs on large datasets over very long periods of time e.g. commensurate with our need to understand the surface impact of global warming. The net gain is twofold: greater end-user empowerment; and a more exciting field of thought-provoking opportunities for model builders.

Neuroemulation has been employed on numerous occasions to produce a quicker groundwater model, delivering processing speeds, which can be up to two orders of magnitude faster. Each solution is subsequently coupled to a genetic algorithm and used to produce an optimal groundwater remediation strategy. The simulated aquifer contained a dissolved contaminant plume and different pump-and-treat abstraction and/or injection options are evaluated to discover the optimum number, location and pumping rates for remediation wells.

(i) Rogers \& Dowla (1994) tested different remediation strategies for multiple contaminant plumes using a hypothetical heterogeneous aquifer. Their work followed the advection-dispersion method for solute transport modelling. Modelling adopted a discrete set of pumping rates i.e. maximum permitted pumping or not pumping. Training examples were obtained from numerous simulation scenarios using 2-D hybrid finite difference/ finite element flow and transport code (Voss, 1984).

(ii) Rao \& Jamieson (1997) performed similar investigations on a simplified but representative approximation to a real aquifer contaminated with chlorinated solvents. The aquifer was assumed to be confined, homogenous and isotropic. Emulation again involved two discrete representations of pumping rates and examples developed using the 2-D hybrid finite difference/ finite-element flow and transport code: FDMOD.

(iii) Aly \& Peralta (1999) modelled observed records for a real single-layer aquifer contaminated with trichloroethylene but did not opt to develop their own physical process code: preferring instead to use a combination of two established international mathematical models: MODFLOW (McDonald \& Harbaugh, 1983; 1988) and MT3D (Zheng, 1990). The former is a 3-D finite-difference ground-water 
flow model; the latter is a 3-D solute transport model that simulates advection, dispersion and chemical reactions of dissolved constituents in groundwater systems.

Parkin and associates (Parkin et al., 2007; Birkinshaw et al., 2008) neuroemulated predicted river-aquifer 'interactions' originating from the complex process-based distributed integrated catchment modelling system SHETRAN (Ewen et al., 2000). Their motivation was to provide a means for rapidly assessing the impact of groundwater abstractions on river flow. Modelling sought to capture different controlling factors, by means of a generic model for different types of river-aquifer system in England and Wales. Hypothetical case studies were used to develop a neuroemulator. SHETRAN required information on recharge and groundwater abstractions plus parameter values for different hydrogeological settings. The simulations were also transient and involved time varying recharge. The original model delivered 74 self-consistent outputs: comprising time series for flow depletion at the catchment outlet, spatial patterns of flow depletions along a river channel and water table drawdowns at various points around the abstraction well. To reduce that number a generalised family of well-behaved curves were fitted to certain outputs: shape parameters being used to represent four curves, in which individual points formed part of a continuous response from SHETRAN. The generic emulator proved to be an efficient tool for representing the impact of groundwater abstractions, across a wide range of conditions. It was also successfully tested on a field dataset for a chalk aquifer i.e. Winterbourne Stream (Lambourn Catchment, Thames Basin). Their reported method swiftly reproduced detailed processbased evaluations but it also highlighted the potential for developing generic emulators, which are not tied to a specific dataset, and/or for adopting non-physical outputs in a NN.

\section{v. Providing model calibration response surfaces}

Neuroemulation is primarily focussed on delivering faster and/or more efficient equivalents; but it can also be used to support traditional modelling operations. For example, a substantial speed-up in calibration (parameter estimation) and model assessment procedures can be invoked by means of an emulator. The development of an input-output response surface can also be quicker and better for other reasons, since the initial number of complex mathematical realisations required to produce an acceptable outcome can be much lower: small gaps can be in-filled; hydraulic insight can be applied in selecting strategic/tactical records, in particular for large and complex field sites, supporting further acceleration and perhaps a better overall result. Field scale applications which demand the use of complex physical models - containing hundreds of parameters - requiring slow and complicated numerical optimisation procedures would clearly benefit.

Liong \& Chan (1993) neuroemulated predicted storm event runoff outputs originating from the widely-used Storm Water Management Model (SWMM: Huber et al., 1982). The motivation behind their experiment was to develop a functional response surface that related model calibration parameters to final model output - similar to the full secondorder polynomial procedure of Ibrahim \& Liong (1992) - from which optimum settings could thereafter be identified. SWMM is a dynamic physically-based deterministic rainfallrunoff model which is used to perform single event or long-term (continuous) simulations of runoff quantity and quality from primarily urban areas. SWMM was used to deliver simulated runoff volumes for the urbanised Upper Bukit Timah catchment in Singapore. Ten single-burst storm event records were considered. Three representative storms were used to provide a modelling dataset: their selected storms portraying upper, intermediate and lower magnitude scenarios of the available rainfall record. The other storms were reserved for out-of-sample testing. For each individual storm, 273 different realisations of eight physical modelling parameter values were implemented. Bounded parameter search was performed, within a physically meaningful range, by 
means of random sampling from a uniform distribution. The required response surface could thereafter be constructed. The nine neuroemulator inputs comprised eight calibration parameters plus rainfall volume: predicted output was runoff volume. The simulation period required for response surface development was reduced from seven hours for the equivalent mathematical procedure to about one minute or less for the neuroemulator. The neuroemulator also yielded relatively low prediction error: ranging from $2 \%$ to $5 \%$ on their testing datasets.

Khu et al. (2004) neuroemulated predicted discharge outputs originating from the MIKE11 NAM model (Nedbor Afstromning Modele: Nielsen \& Hansen, 1973). Like Liong \& Chan (1993), they sought to develop a functional response surface that related model parameters to final model output. Their hybrid solution was intended to reduce the number of simulation runs required, improving the feasibility of automatic calibration, by addressing the challenges of modelling a 'changing landscape' i.e. as more cases are gathered, the neuroemulator will require adjustment, such that greater efficiencies might be gained from performing search and update in a dynamic manner. NAM is a general purpose lumped conceptual hydrological rainfall-runoff model in which four interrelated storages are used to represent different physical elements of a catchment. The nine most important parameters of the model were to be determined by calibration - see Madsen (2000). First, a genetic algorithm is used to search for an initial population of preferred solutions, in much the same way as any other optimisation routine might be performed. This information is used in a neuroemulator to construct an initial response surface, which is thereafter applied in a second genetic algorithm loop, as a rapid initial selection or rejection filter of candidate solutions, prior to implementing best-individualbased updating of the neuroemulator with NAM. The proposed method was tested on daily datasets for the Treggevaede catchment in Denmark. The results were comparable to that of a standard genetic algorithm, but the number of mathematical model runs required was reduced by $60 \%$.

\section{vi. Supplying surrogate parts for system optimisation}

Neuroemulation can be used to deliver independent standalone applications; but it could also be used to develop smaller replacement components, which subsequently act as an integrated part of some larger system. The act of partitioning a larger problem into a set of smaller modelling challenges will hopefully result in the production of superior internal components and an improved overall model. If one or more slow(er) components inside a complex system are replaced by emulators, the original mechanism will run much faster, whilst from an overall conceptual position, everything else remains largely unaltered. Neuroemulation also offers a greater degree of independence from structures and methods related to the original model or program, something that might be very important in the case of a dedicated software product. It will, moreover, support 'ease of extension': since to encompass alternative inputs and/or mechanisms and implement different objective functions is a straightforward matter.

Solomatine and associates (Solomatine \& Avila Torres, 1996; Dibike et al., 1999) neuroemulated predicted downstream water level outputs originating from MIKE-11: an industry standard hydrodynamic modelling system (Havnø et al., 1995). Two computational modules were involved: (i) NAM (described earlier) and (ii) HD, its core 1D hydrodynamic component. Their primary goal was one of multi-criterial decision making for a 3-reservoir system in the Apure River Basin of Venezuela: operational demands required water releases (turbine throughput and bottom outlet) for power generation; operational constraints included minimal water releases for navigational, industrial, ecological and drinking purposes. The overall river control process was to be optimised by means of dynamic programming, requiring a hydrodynamic model of the river system to be incorporated into a standard optimisation loop. MIKE-11 was used to perform the required downstream water level simulations using observed datasets but is: (i) menu driven i.e. modules could not be run unattended or controlled from an 
external program; and (ii) the time needed to perform an optimisation loop would have been prohibitively long. Neuroemulators were instead used to predict downstream depth at points of interest: receiving as input upstream sub-catchment discharges, releases from reservoirs, plus initial water level. The output was final water level. Each neural solution was converted into source code and compiled to provide a small compact executable, that was fast to run, and could be incorporated in the reservoir operation optimisation loop as a direct replacement for MIKE-11; different objective functions and/or optimisation procedures could also thereafter be applied in a straightforward manner.

Wang \& Jamieson (2002) neuroemulated predicted downstream biological oxygen demand outputs originating from TOMCAT (Temporal/ Overall Model for CATchments: Bowden \& Brown, 1984; Cox, 2003): a process-based river water quality simulation model developed by Thames Water. TOMCAT was used to predict downstream consequences arising from treated effluent discharged into a river for different combinations of either: (i) a fixed-emission standard, enabling site selection; or (ii) individual standards for different plants so as to meet in-stream water quality requirements, enabling simultaneous site selection/waste load allocation. Their primary goal was cost reduction: modelling sought to minimise the total (capital and operating) cost of treatment under different regulatory scenarios for works situated in the Upper Thames basin of southern England. The overall process was optimised by means of a genetic algorithm. TOMCAT is a complex mathematical "cause and effect" model. It is designed to account for assimilative capacity such as in-stream dilution, dispersion and natural purification (reoxygenation): but is computationally demanding and not easily incorporated into a standard optimisation loop. Neuroemulation delivered a simpler and faster mechanism, supporting rapid, near optimal convergence, under different combinations of plants, standards and hydrological conditions. Increased processing speed, however, was supported by other massive computational savings. The number of TOPCAT model runs needed was massively reduced in the development of a neural response function: for a single river quality objective, from a full search necessitating in excess of over 5000 direct calls, to 500 runs considered sufficient to produce an appropriate spread of input-output pairings for building a NN.

Muleta \& Nicklow (2004) neuroemulated predicted sediment yield and agricultural profit, at the level of a hydrologic response unit, originating from the Soil and Water Assessment Tool (SWAT: Arnold et al., 1998; American Society of Civil Engineers, 1999). SWAT is a physically-based distributed river-basin-scale public domain model which was developed to quantify the impact of land management practices in large, complex watersheds. Their primary goal was speed-up: so as to improve the practical utility of an operational decision support tool, from a typical user perspective, by installing a neuroemulator replacement for the SWAT hydrological simulation component contained inside a previously developed multiobjective decision-support system. That particular routine formed part of a larger hybrid-coupling that was designed to aid in reducing the impact(s) of erosion while considering social and economic dynamics of a watershed. The overall process was optimised by means of a 'Strength Pareto Evolutionary Algorithm'. That mechanism searched for optimal or near-optimal watershed landscapes, defined as that combination of land use and farm management practises, at the spatial scale of a farm field, which simultaneously minimises sediment yield and maximises net agricultural profit over a specified period (Muleta \& Nicklow, 2002; Muleta, 2003). The original watershed decision support model took 2.5 CPU days to process Big Creek: a $130 \mathrm{~km}^{2}$ watershed in southern Illinois. Neuroemulation reduced the computational period required to identify preferred landscapes and generate watershed management policies by some $75 \%$ (including dataset creation and model development): run time processing dropped from 63.25 hours to 4.5 minutes.

\section{vii. Streamlining of individual and modular solutions}


Neuroemulation can deliver less complicated modelling solutions, in the form of interpreted or compiled products, which can be much easier to work with i.e. a tool that is less difficult, convoluted, inconsistent, problematic or demanding. This statement might appear contradictory, given NN that are complex parallel processing mechanisms i.e. can be broken down into simple parts, without being simple itself. Their ability, however, to acceptably perform full, partial, augmented or surrogated modelling, will support the rapid production of simpler and less demanding mechanisms. From a practical, operational and managerial viewpoint, such products would be substantially easier to install, administer and resource. Their flexibility and adaptability with regard to inputs and outputs can also be used to deliver sound multi-model couplings, since by means of simplicity, neuroemulators could be used to provide an open ended 'bridging mechanism': relaying diverse information from different models as part of a cascading series.

Hsu et al. (2003) neuroemulated predicted suspended sediment concentration outputs originating from the popular Hydrologic Simulation Program Fortran (HSPF: Bicknell et al., 1997). The motivation behind their experiment was to develop: (i) a less complicated surrogate that demanded fewer, easier/cheaper to acquire inputs; and (ii) a tool that could be operated by non-professional staff i.e. model reduction/simplification. HSPF was considered difficult to support due to its heavy demands for numerous datasets and experienced personnel. This river basin modelling program is used to assess the effects of land-use change, reservoir operations, point or nonpoint source treatment alternatives, flow diversions, etc. It requires continuous temporal records of rainfall, temperature and solar radiation; surface characteristics such as land use patterns; and information on land management practices in order to simulate the processes that occur in a watershed. Flow, sediment, nutrient and pesticide concentrations are all predicted. HSPF was applied to the Chi-Cha-Wan watershed in Central Taiwan. It was used to model Typhoon Seth (calibration) and Typhoon Tim (verification) in 1994. Ten other rainfall records for different typhoon events were thereafter passed through HSPF and its model outputs used to develop a neuroemulator. NN inputs comprised a simple sequence of past rainfall and current discharge records, which were straightforward to collect, meaning that it could be applied in numerous situations where the demands of their original complex model could not be resourced. Their two models provided similar results, but the neuroemulator was quicker to implement and easier to run. Execution times are not reported.

Kamp \& Savenije (2007) neuroemulated four different physical models: a daily lumped conceptual rainfall-runoff model - Hydrologiska Byråns Vattenbalansavdelning (HBV: Bergström \& Forsman, 1973; Lindström et al., 1997), a 30 min 1-D hydraulic river channel routing model (Duflow: www.duflow.nl/), a 30 min estuarine salt intrusion model (Savenije, 1989, 1993, 2005) and a 30 min ecological water quality underwater light model (Secchi-depth Model: Blom, 1992). Each model formed part of a larger loose-coupled 'modular solution': outputs from the rainfall-runoff model, were fed into the hydraulic model, and so on cascading down through the system in a serial manner. The main issue of interest was not emulation per se: it was to encourage simpler and sounder model coupling in which NN deliver a 'bridging mechanism'. The authors recognised an increasing need for different models to be coupled: but also understood that such activities were frequently handicapped by: (i) a requirement to run individual models in particular software packages; (ii) incompatibility issues related to dissimilar data formats and scales; and (iii) an inability to directly modify source code - a problem related to intellectual property rights. Four individual neuroemulators were developed for the Alzette Basin in Luxembourg. Three of the four solutions performed reasonably well: but their salt intrusion model struggled to represent both short term (tidal) and long term (hydrological) processes. The intermediate channel routing NN could nevertheless be used to connect two physical models. However, running four neuroemulators in series, suffered from accumulated error build-up: mainly stemming from the rainfallrunoff and salinity NN. 


\section{viii. Delivering faster time-critical processing}

Neuroemulation can deliver sound modelling solutions, possessing run speeds that are orders of magnitude faster. Speed-up offers clear benefits for both operational and nonoperational applications. Neuroemulators can be used in operational systems where realtime demand places important deadlines, or perhaps mission critical constraints, on the activities and deliverables which must occur between 'event' and 'response'. The replacement of traditional mathematical products with neuroemulators could for instance deliver major improvements in processing speed for decision making and operational control in a dynamic water environment. However, productivity per time unit is also important in other ways, such that methodological improvements regarding the manner in which a particular problem is resolved can deliver strong practical benefits for laboratory modelling i.e. situations containing no fixed quality-of-life or life-threatening deadlines, even if a fast response time, or high performance operation is desired.

Jamieson and associates (Jamieson et al., 2007; Rao \& Alvarruiz, 2007; Salomons et al., 2007; Martinez et al., 2007) neuroemulated predicted hydraulic and water quality behaviour in pressurised pipe networks originating from a complex simulation model: EPANET (Rossman, 2000). EPANET is public-domain water distribution system modelling software developed by the United States Environmental Protection Agency. It performs extended-period simulation of pipeline distribution systems and was developed to help water utilities maintain and improve their delivery of water to consumers. To estimate the physical consequences of different pump and value settings for fluctuating spatial and temporal patterns of demand necessitates a process-based hydraulic simulation model. The computational demands of such approaches are nevertheless substantial and require greater processing efficiencies to be acquired: so as to support real-time, nearoptimal control of larger distribution networks, possessing mechanical operational apparatus which must be adjusted at frequent intervals. Neuroemulators were used to capture the complex domain knowledge base of this hydraulic simulation model in an accurate and robust manner under different test conditions. The reported gains in computational speed-up to predict the consequences of different control settings were x10 for a hypothetical 41-pipe 19-node 'Any Town" network (Walski et al., 1987). Higher gains were reported using larger emulators coupled to a genetic algorithm optimisation procedure which matched control settings to operating costs and water demand forecasts: $\times 25$ for a 112-node 126-pipe Haifa-A network (a sub-set of the water distribution network for Haifa in northern Israel); x94 for a 725-node 772-pipe city-scale network of Valencia in Spain.

Cullmann and associates (Schmitz \& Cullmann, 2008; Cullmann et al., 2009) neuroemulated predicted discharge outputs originating from two coupled public-domain products: (i) the detailed grid- and physically-based distributed rainfall-runoff hydrologic Water Flow and Balance Simulation Model (WaSiM-ETH: Gurtz et al., 2000); and, optionally, to cover extended flooding or significant backwater effects at confluences (ii) the Hydrologic Engineering Center River Analysis System (HEC-RAS: Brunner, 2002). Their hydrodynamic model was parameterised for the Freiberger Mulde catchment in the Ore Mountains of Germany. The precipitation record was thereafter enhanced, by including synthetic scenarios derived from a stochastic rainstorm generator, which mirrored typical meteorological catchment behaviour - so as to represent all possible 'constellations of flood formation'. The generator settings were based on meteorological analysis and operating the hydrodynamic model on their revised dataset enabled certain particulars to be considered as 'state feature vectors'. This resulted in a database of input/output vectors, which is thereafter completed by generally available hydrological and meteorological data for characterising catchment conditions prior to each storm event. Their solution was considered sound: it was also able to reproduce the dynamics of a real flood. The reported gains in computational speed-up exceeded $x 100$. Such rapidity is important in delivering flash flood warnings i.e. where every minute counts. It 
would permit real-time analysis and management of different structural defence scenarios, if such items were to be included. Their methodology was also applied to an ensemble of temporal and spatial rainfall scenarios containing 200 members - facilitating a straightforward evaluation of meteorological forecast uncertainty.

\section{SUMMARY AND CONCLUSIONS}

This paper has provided an introduction to the subject of neuroemulation and a structured categorisation of on-going developments in an expanding field of water resources modelling. The authors recognise that the methodology employed in synthesising and collating relevant literature is counter to the contemporary norms by which many reviews are conducted (i.e. extensive database searching). However, we argue that in exemplifying the benefits of the newly-emerging sub-discipline of neuroemulation, for which a standard terminology is as yet unrecognised in water resources, the adoption of a qualitative appraisal of the literature based on expert knowledge is an appropriate starting point. There is a possibility that more sophisticated and comprehensive full-text search methodologies may identify additional relevant studies that can build on those presented here, particularly if soft or fuzzy search schema are employed. Conducting such a review represents a future study worthy of consideration.

It is argued that such neuro-emulation activities have not been awarded sufficient recognition or given due past credit in the water resources domain. In part this may be attributed to the need for a consistent and coherent vocabulary surrounding emulation activities, which makes important applications hard to identify in the research literature. If the field is to become better established, some meaningful agreement that delivers stronger recognition and appropriate and consistent language is required. However, one could also speculate that this lack of a developed nomenclature, is simply symptomatic of a more general lack of recognition of the importance of emulation by researchers. Indeed, the process of using one model to represent another model, is sometimes considered to be less scientific or less elegant than resolving other, more pressing, or more controversial, modelling challenges.

The literature presented here challenges recent concerns that further investigation into the use of NN tools for water resources modelling might prove to be an academic cul-desac (Wilby et al., 2003, p.164) by highlighting their potential implementation as emulators. Indeed, when NN are used to perform emulation, particularly in situations where out-of-sample testing is paramount and no physical hydrological considerations are involved, arguments about the lack of transparency or hydrological knowledge in NN solutions become less important. Indeed, in this context the potential value of NN research is more evident. The following caveats should nevertheless be noted:

- The time and effort needed to construct a NN solution must be offset against potential gains;

- Emulator performance will depend on the performance of the parent model; and

- Emulator performance could deteriorate if it is applied beyond the range of conditions used in development.

To conclude, three potential avenues for further research emerge from the literature presented in this review:

\section{Neuroemulator choice and evaluation}

Most reported experiments involved a single individual neuroemulator. No comparison of different types of emulator or different emulation strategies was provided. Thus, two key questions remain unanswered: (i) how should the form and function of a neuroemulator to be determined; and (ii) how is the preferred neuroemulator mechanism for a particular situation to be decided? 
Several major models have been emulated to good effect but no comprehensive evaluation was reported: neuroemulator mechanisms were only tested for accuracy. Following Jin et al. (2000), it is our belief that various factors contribute to the success of a given emulator, including nonlinearity of model behaviour, dimensionality and data sampling, and internal parameter settings for the method under test. They contended that multiple metrics should be considered for comparison, including accuracy, efficiency, robustness, model transparency, and simplicity. Knowledge of performance and the impact of contributing factors to their success is of utmost importance to designers when trying to choose an appropriate method for emulating a particular application. The development of neuroemulators in most reported instances equated to a straightforward mundane operation: but experiments performed on perfect datasets, that were designed to provide a good fit to the simulator, might deliver a different product to a solution trained on real world observations that contained random noise or systematic error in either inputs and/or outputs. The adoption or inclusion of modified and disrupted inputoutput parings should in consequence be tested.

\section{Methods for constraining neuroemulators}

In choosing and evaluating a neuroemulator, the satisfaction of constraints will be an important factor since a neuroemulator cannot take specific advantage of the original model structure; making it vulnerable to the production of inappropriate solutions and/or outputs. Indeed, a neuroemulator must provide an accurate representation of the simulation model in the vicinity of the global optimum, but it is also vital that an appropriate representation is provided at the margins. If the neuroemulator wrongly indicates that a particular solution is feasible and/or the output is correct, the search process could be directed into an undesirable region of the solution space e.g. a local sub-optimum as opposed to a global optimum.

\section{Methods for efficient neuroemulator development}

Most studies that were reviewed involved the production of massive datasets; a tedious and time consuming business. The reported neuroemulators were developed on a random sampling of the solution space but more efficient and effective methods could be used. These might include the adoption of non-uniform sampling strategies, as reported in other subjects e.g. performing a local search around optimal solutions using the original simulation model. Similarly, the use of neuroemulators is of particular interest in the case of large models possessing numerous inputs and outputs. However, for really massive simulators requiring hundreds of inputs and parameters to be incorporated, some sort of 'screening' or 'input / parameter reduction' procedure would be very useful. The different potential methodologies that might be adopted could be explored.

\section{ACKNOWLEDGEMENTS}

The pioneering spirit of the original paper authors must be recognised. Their initial enthusiasm and imagination in developing novel applications has created an innovative field of research, which offers sound potential and strong practical rewards for water resources modellers and a wider stakeholder market. It delivered the core material for our reported analysis. Two anonymous reviewers provided constructive comments and helpful suggestions for improving the first draft of our strategic appraisal of published material. Their time, effort and insightful input was very much appreciated and such important contributions are duly acknowledged.

\section{REFERENCES}

Abrahart, R.J., Anctil, F., Coulibaly, P., Dawson, C.W., Mount, N.J., See, L.M., Shamseldin, A.Y., Solomatine, D.P., Toth, E. \& Wilby, R.L. (submitted) Two 
decades of anarchy? Emerging themes and outstanding challenges for neural network modelling of surface hydrology. Submitted to: Progress in Physical Geography.

Abrahart, R.J. \& See, L.M. (2007) Neural network modelling of non-linear hydrological relationships, Hydrology and Earth System Sciences 11(5), 1563-1579.

Ahmad, S., \& Simonovic, S.P. (2005) An artificial neural network model for generating hydrographs from hydro-meteorological parameters, Journal of Hydrology, 315(14), 236-251.

Aly, A.H \& Peralta, R.C. (1999) Optimal Design of Aquifer Cleanup Systems Under Uncertainty using a Neural Network and a Genetic Algorithm, Water Resources Research 35(8), 2523-2532.

Arnold, J.G., Srinivasan, R., Muttah, R.S. \& Williams, J.R. (1998) Large area hydrologic modeling and assessment part I: Model development, Journal of the American Water Resources Association 34(1), 73-89.

American Society of Civil Engineers (1999) GIS Modules and Distributed Models of Watersheds. American Society of Civil Engineers, Reston, Virginia, USA.

Bergström, S. \& Forsman, A. (1973) Development of a conceptual deterministic rainfallrunoff model, Nordic Hydrology 4(3), 147-170.

Bicknell, B.R., Imhoff, J.C., Kittle, J.L., Jr., Donigian, A.S., Jr. \& Johanson, R.C. (1997) Hydrological Simulation Program - FORTRAN: User's Manual for Version 11, Report EPA/600/R-97/080, U.S. Environmental Protection Agency, National Exposure Research Laboratory, Athens, Georgia, USA, 755 pp.

Birkinshaw, S. J., Parkin, G. \& Rao, Z. (2008) A hybrid neural networks and numerical models approach for predicting groundwater abstraction impacts, Journal of Hydroinformatics 10(2), 127-137.

Blanning, R.W. (1975) The construction and implementation of metamodels. Simulation 24(6), 177-184.

Blom, G. (1992) Licht onder water, Het belang van extinctiemetingen, Landbouwuniversiteit Wageningen, Vakgroep. Waterkwaliteitsbeheer en Aquatische Oecologie, Wageningen, The Netherlands.

Bond, F.W., Chery, D.L. \& Simpson, E.S. (1979) A Parametric model calibrated with a physically based model for runoff prediction from ungaged streams, Water resources Bulletin 25(6), 1640-1652.

Bowden, K. \& Brown, S.R. (1984) Relating Effluent Control Parameters to River Quality Objectives Using a Generalised Catchment Simulation Model, Water Science Technology 16(5-7), 197-205.

Broad, D.R., Dandy, G.C. \& Maier, H.R. (2005) Water Distribution System Optimization Using Metamodels. Journal of Water Resources Planning and Management 131(3), 172-180.

Brunner, G.W. (2002) HEC-RAS River Analysis System - Hydraulic Reference Manual. Hydrological Engineering Center, US Army Corps of Engineers, Davis, CA, USA.

Chorley, R.J. \& Haggett, P. (1967) Eds. Models in Geography. Methuen \& Co. Ltd., London, UK.

Chuta, P. \& Dooge, J.C.I. (1990) The shape parameters of the geomorphologic unit hydrograph, Journal of Hydrology 117(1-4), 81-79.

Cox, B.A. (2003) A review of currently available in-stream water-quality models and their applicability for simulating dissolved oxygen in lowland rivers, Science of The Total Environment 314-316, 335-377.

Cullmann, J., Krausse, T. \& Philipp, A. (2009) Communicating flood forecast uncertainty under operational circumstances. Journal of Flood Risk Management 2(4), 306314.

Dawson, C.W., Abrahart, R.J., Shamseldin, A.Y. \& Wilby, R. L. (2006) Flood estimation at ungauged sites using artificial neural networks, Journal of Hydrology, 319 (1-4), 27-41.

Dibike, Y., Solomatine, D.P. \& Abbott, M.B. (1999) On the encapsulation of numericalhydraulic models in artificial neural network, Journal of Hydraulic Research 37(2), $147-161$. 
Ewen, J., Parkin, G. \& O'Connell, P.E. (2000) SHETRAN: Distributed River Basin Flow and Transport Modeling System, ASCE Journal of Hydrologic Engineering 5(3), 250258.

French, M.N., Krajewski, W.F. \& Cuykendall, R.R. (1992) Rainfall forecasting in space and time using a neural network, Journal of Hydrology 137(1-4), 1-31.

Friedman, L.W. \& Pressman, I. (1988) The Metamodel in Simulation Analysis: Can It Be Trusted?, Journal of the Operational Research Society 39(10), 939-948.

Greenfield, B. (1984) The Thames Catchment Model. Internal Report, Technology and Development Division, Thames Water, Reading, UK.

Gurtz, J., Zappa, M., Jasper, K., Lang, H., Badoux, A., Verbunt, M., \& Vitvar, T. (2000) Modelling and validation of runoff and its components in Swiss Pre-Alpine and Alpine catchments. In: Proceedings of the International Workshop on Runoff Generation and Implications for River Basin Modelling, Freiburg i.Br., Germany 912 October 2000, Freiburger Hefte. 30, 206-220.

Havnø, K., Madsen, M.N. \& Dørge, J. (1995) MIKE 11 - a generalized river modelling package. In: Singh, V.P., Ed. Computer Models of Watershed Hydrology, Water Resources Publications, Colorado, USA, pp. 733-782.

Hsu, C.Y., Lee, H.Y. \& Lin, Y.L. (2003) Estimation of sediment yields in a watershed area using ANN method. In: Brebbia, C.A. (Ed.) River Basin Management II (Transactions of the Wessex Institute, Ecology and the Environment Vol. 60, Progress in Water Resources Vol. 7), WIT Press, Southampton, UK, pp. 461-470.

Huber, W.C., Heaney, J.P., Nix, S.J., Dickonson, R.E. \& Polman, D.J. (1982) Storm Water Management Model, User's Manual, Version III. U.S. Environmental Protection Agency, Cincinnati, Ohio, USA.

Ibrahim, Y. \& Liong (1992) Calibration Strategy for Urban Catchment Parameters, Journal of Hydraulic Engineering 118(11), 1550-1570.

Jamieson, D.G., Shamir, U., Martinez, F. \& Franchini, M. (2007) Conceptual design of a generic, real-time, near-optimal control system for water-distribution networks, Journal of Hydroinformatics 9(1), 3-14.

Jin, R., Chen, W. \& Simpson, T.W. (2001) Comparative studies of metamodeling techniques under multiple modeling criteria, Structural and Multidisciplinary Optimization, 23(1), 1-13.

Kamp, R.G. \& Savenije, H.H.G. (2007) Hydrological model coupling with ANNs, Hydrology and Earth System Sciences 11(6), 1869-1881.

Khu, S-T., Savic, D., Liu, Y. \& Madsen, H. (2004) A fast Evolutionary-based MetaModelling Approach for the Calibration of a Rainfall-Runoff Model. In: Pahl-Wostl, C., Schmidt, S., Rizzoli, A.E. and Jakeman, A.J. (eds) Complexity and Integrated Resources Management, Transactions 2nd Biennial Meeting of the International Environmental Modelling and Software Society, University of Osnabrück, Germany 14-17 June 2004. iEMSs: Manno, Switzerland. Vol. 1. pp. 147-152.

Krajewski, W.F. \& Rodriguez-Iturbe, I. (1990) Rainfall Simulation Models - RMODC3. Iowa Institute of Hydraulic Research and Department of Civil and Environmental Engineering, University of Iowa, Iowa City, Iowa, USA.

Kumar, B., Sreenivasulu, G. \& Ramakrishna Rao, A. (2010) Metamodel-based design of alluvial channels at incipient motion subjected to seepage. Hydrological Sciences Journal 55(3), 459-466.

Lindström, G., Gardelin, M., Johansson, B., Persson, M. \& Bergström, S. (1997) Development and test of the distributed HBV-96 hydrological model, Journal of Hydrology 201(1-4), 272-288.

Liong, S.Y. \& Chan, W.T. (1993) Runoff Volume Estimates with Neural Networks. In: Topping, B.H.V. and Khan, A.I. (Eds.) Neural Networks and Combinatorial Optimization in Civil and Structural Engineering, Proceedings Third International Conference on the Application of Artificial Intelligence to Civil and Structural Engineering, Edinburgh, UK, 17-19 August 1993, Civil-Comp Press, Stirling, UK, pp. 67-70.

Madsen, H. (2000) Automatic calibration of a conceptual rainfall-runoff model using multiple objectives. Journal of Hydrology 235(3-4), 276-288. 
Martínez, F., Hernández, V., Alonso, J.M., Rao, Z. \& Alvisi, S. (2007) Optimizing the operation of the Valencia water-distribution network, Journal of Hydroinformatics 9(1), 65-78.

McDonald, M.G. \& Harbaugh, A.W. (1983) A modular three-dimensional finite-difference ground-water flow model, Open-File Report 83-875. U.S. Geological Survey, 528 pp.

McDonald, M.G. \& Harbaugh, A.W. (1988) A modular three-dimensional finite-difference ground-water flow model, Techniques of Water-Resources Investigations, Book 6, U.S. Geological Survey, 586 pp.

Mein, R.H., Laurenson, E.M. \& McMahon, T.A. (1974) Simple nonlinear model for flood estimation, Journal of Hydraulics Division - American Society of Civil Engineers, 100(HY11), 1507-1518.

Minns, A.W. \& Hall, M.J. (1996) Artificial neural networks as rainfall-runoff models, Hydrological Sciences Journal 41(3), 399-417.

Moreno, J., Abudu, S., Bawazir, A.S. \& King, J.P. (2010) Comment on 'Kisi, Ö. 2009. Daily pan evaporation modelling using multi-layer perceptrons and radial basis neural networks. Hydrological Processes 23: 213-223'. Hydrological Processes 24(21), $3115-3118$.

Muleta, M.K. (2003) A Decision Support System for the Management of Non-Point Source Pollution from Watersheds. Unpublished Ph.D. Thesis, College of Engineering, Southern Illinois University at Carbondale, Carbondale, Illinois, USA.

Muleta M.K. \& Nicklow, J.W. (2002) Evolutionary algorithms for multiobjective evaluation of watershed management decisions, Journal of Hydroinformatics 4(2), 83-97.

Muleta, M.K. \& Nicklow, J.W. (2004) Joint application of artificial neural networks and evolutionary algorithms to watershed management, Journal of Water Resources Management 18 (5), 459-482.

Nash, J.E. (1957) The form of the instantaneous unit hydrograph, International Association of Scientific Hydrology Publication No. 45. Vol 3. pp. 114-120.

Nielsen, S.A. \& Hansen, E. (1973) Numerical simulation of the rainfall runoff process on a daily basis, Nordic Hydrology 4(3), 171-190.

Parkin, G., Birkinshaw, S.J., Younger, P.L., Rao, Z. \& Kirk,S. (2007) A numerical modelling and neural network approach to estimate the impact of groundwater abstractions on river flows, Journal of Hydrology 339(1-2), 15- 28.

Quinn, P. (2004) Scale appropriate modelling: representing cause-and-effect relationships in nitrate pollution at the catchment scale for the purposes of catchment scale planning, Journal of Hydrology 291(3-4), 197-217.

Rao, Z. \& Alvarruiz, F. (2007) Use of an artificial neural network to capture the domain knowledge of a conventional hydraulic simulation model, Journal of Hydroinformatics 9(1), 15-24.

Rao, Z. \& Jamieson, D.G. (1997) The use of neural networks and genetic algorithms for the design of groundwater remediation schemes, Hydrology and Earth System Sciences 1(2), 345-355.

Reichert, P., White, G., Bayarri, M.J. \& Pitman, E.B. (2011) Mechanism-based emulation of dynamic simulation models: Concept and application in hydrology, Computational Statistics and Data Analysis 55(4), 1638-1655.

Rodriguez-Iturbe, I. \& Eagleson, P.S. (1987) Mathematical models of rain storm events in space and time, Water Resources Research 23(1), 181-190.

Rogers, L.L. \& Dowla, F.U. (1994) Optimization of groundwater remediation using artificial neural networks with parallel solute transport modeling, Water Resources Research 30(2), 457-481.

Rossman, L.A. (2000). EPANET 2 Users Manual. US Environmental Protection Agency, Water Supply and Water Resources Division, National Risk Management Research Laboratory, Cincinnati, OH, USA, Report No EPA/600/R-00/057, 200 pp.

Rosso, R. (1984) Nash Model Relation to Horton Order Ratios, Water Resources Research 20(7), 914-920. 
Salomons, E., Goryashko, A., Shamir, U., Rao, Z. \& Alvisi, S. (2007) Optimizing the operation of the Haifa-A water-distribution network, Journal of Hydroinformatics 9(1), 51-64.

Savenije, H.H.G. (1989) Salt intrusion model for high water slack, low water slack, and mean tide on spread sheet. Journal of Hydrology 107(1-4), 9-18.

Savenije, H.H.G. (1993) Predictive model for salt intrusion in estuaries. Journal of Hydrology 148(1-4), 203-218.

Savenije, H.H.G. (2005) Salinity and Tides in Alluvial Estuaries. Elsevier Science Ltd.

Schmitz, G.H. \& Cullmann, J. (2008) PAI-OFF: A new proposal for online flood forecasting in flash flood prone catchments. Journal of Hydrology 360(1-4), 1- 14.

Shamseldin, A.Y. \& Nash, J.E. (1998) The Geomorphological Unit Hydrograph: A Critical Review, Hydrology and Earth System Sciences 2(1), 1-8.

Shrestha, D.L., Kayastha, N. \& Solomatine, D.P. (2009) A novel approach to parameter uncertainty analysis of hydrological models using neural networks, Hydrology and Earth System Sciences, 13(7), 1235-1248.

Slobodkin, L.B. (1958) Meta-Models in Theoretical Ecology, Ecology 39(3):550-551.

Solomatine, D.P. \& Avila Torres, L.A. (1996) Neural network approximation of a hydrodynamics model in optimizing reservoir operation. In: Müller, A. (Ed.) Hydroinformatics 96: Proceedings Second International Conference on Hydroinformatics, Zurich, Switzerland, 9-13 September 1996, A.A. Balkema Publishers, Rotterdam, The Netherlands, Vol. 1, 201-206, 1996.

Swingler, K. (1996) Applying Neural Networks: A Practical Guide, Academic Press Ltd., London, UK, $303 \mathrm{pp}$.

Van den Boogaard, H.F.P. \& Kruisbrink, A.C.H. (1996) Hybrid modelling by integrating neural networks with numerical models. In: Müller, A. (Ed.) Hydroinformatics 96: Proceedings Second International Conference on Hydroinformatics, Zurich, Switzerland, 9-13 September 1996, A.A. Balkema Publishers, Rotterdam, The Netherlands, Vol. 2, 471-478, 1996.

Voss, C.I. (1984) A finite-element simulation model for saturated-unsaturated, fluiddensity-dependent ground-water flow with energy transport or chemically-reactive single-species solute transport, U.S. Geological Survey, Water-Resources Investigations, Report 84-4369, 409 pp.

Walski, T.M., Brill, E.D. Jr, Gessler, J., Goulter, I.C., Jeppson, R.M., Lansey, K.E., Lee, H.L., Leibman, J.C., Mays, L.W., Morgan, D.R. \& Ormsbee, L.E. (1987) Battle of the network models: epilogue, Journal of Water Resources Planning and Management 113(2), 191-203.

Wang, C.G. \& Jamieson, D.G (2002) An objective approach to regional wastewater treatment planning, Water Resources Research 38(3), 1022, doi:10.1029/2000WR000062

Wilby, R.L., Abrahart, R.J. \& Dawson, C.W. (2003) Detection of conceptual model rainfall-runoff processes inside an artificial neural network, Hydrological Sciences Journal 48(2), 163-181.

Wilby, R.L., Greenfield, B. \& Glenny, C. (1994) A coupled synoptic-hydrological model for climate change impact assessment, Journal of Hydrology 153(11), 265-290.

Wu, C.L., Chau, K.W. \& Li, Y.S. (2009) Methods to improve neural network performance in daily flows prediction, Journal of Hydrology, 372 (1-4), 80-93.

Zhao, R-J. (1992) The Xinanjiang model applied in China, Journal of Hydrology 135(14), 371-381.

Zhao, R-J., Zhang, Y-L., Fang, L-R., Liu, X-R. \& Zhang, Q-S. (1980) The Xinanjiang model. In: Hydrological Forecasting: Proceedings of the Symposium on the Application of Recent Developments in Hydrological Forecasting to the Operation of Water Resource Systems, Oxford, April 1980, International Association of Hydrological Sciences Press, Wallingford, UK, IAHS Publication No. 129, pp. 351356.

Zheng, C. (1990) MT3D, A modular three-dimensional transport model for simulation of advection, dispersion and chemical reactions of contaminants in groundwater 
systems, Report prepared for: The United States Environmental Protection Agency, Robert S. Kerr Environmental Research Laboratory, Ada, Oklahoma, USA, 170 pp. 


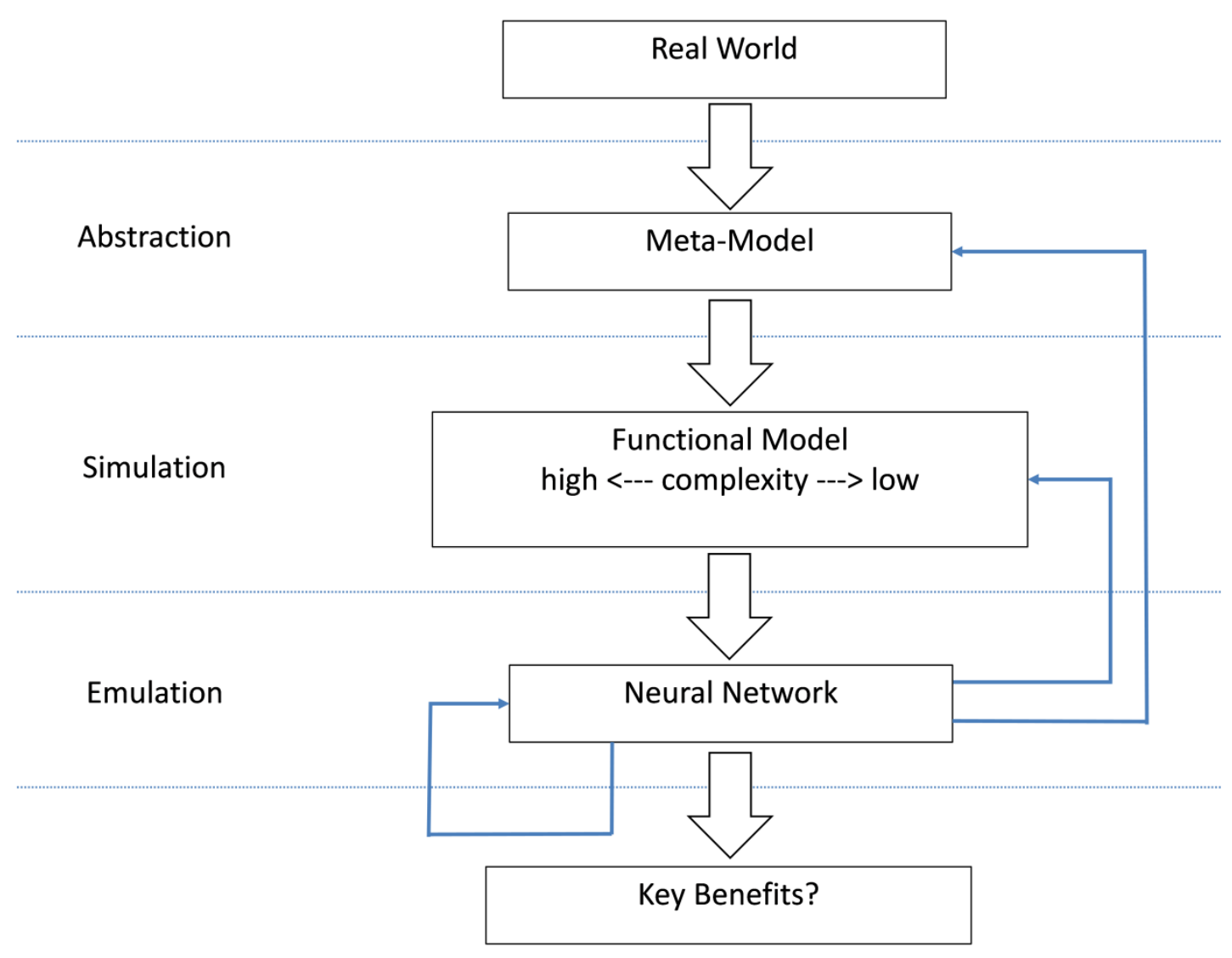

Fig 1: Hierarchical rationalisation of existing modelling nomenclature including potential pathways for neural network emulator feedback 
Number of papers

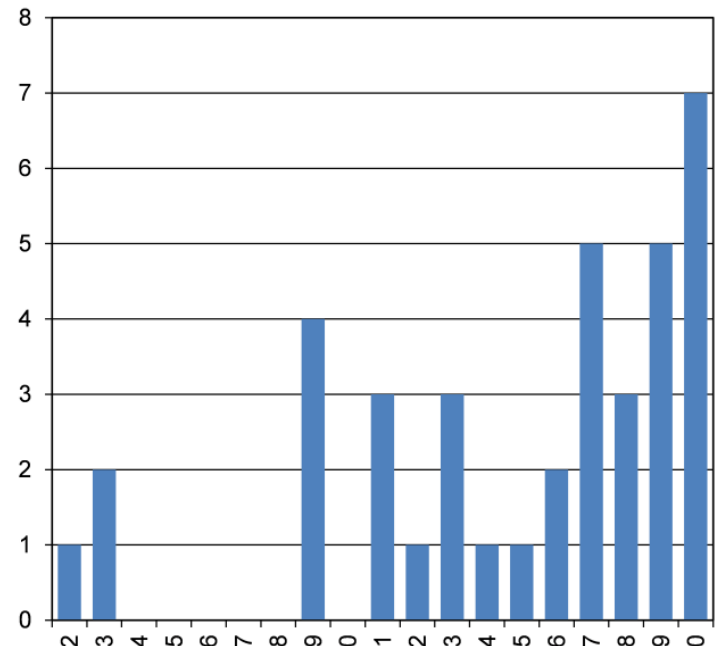

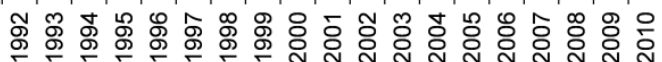

Number of citations

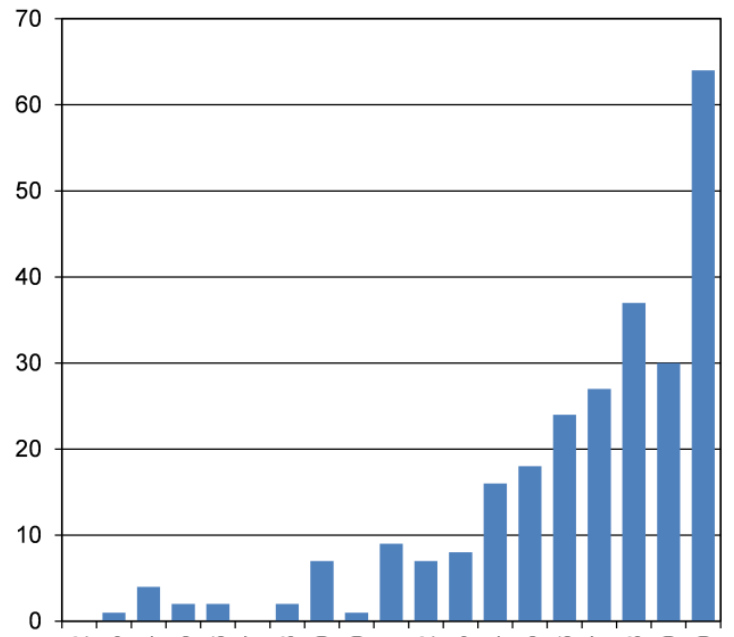

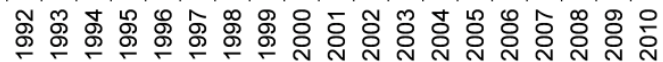

Fig 2: Findings returned from query run on Web of Knowledge 


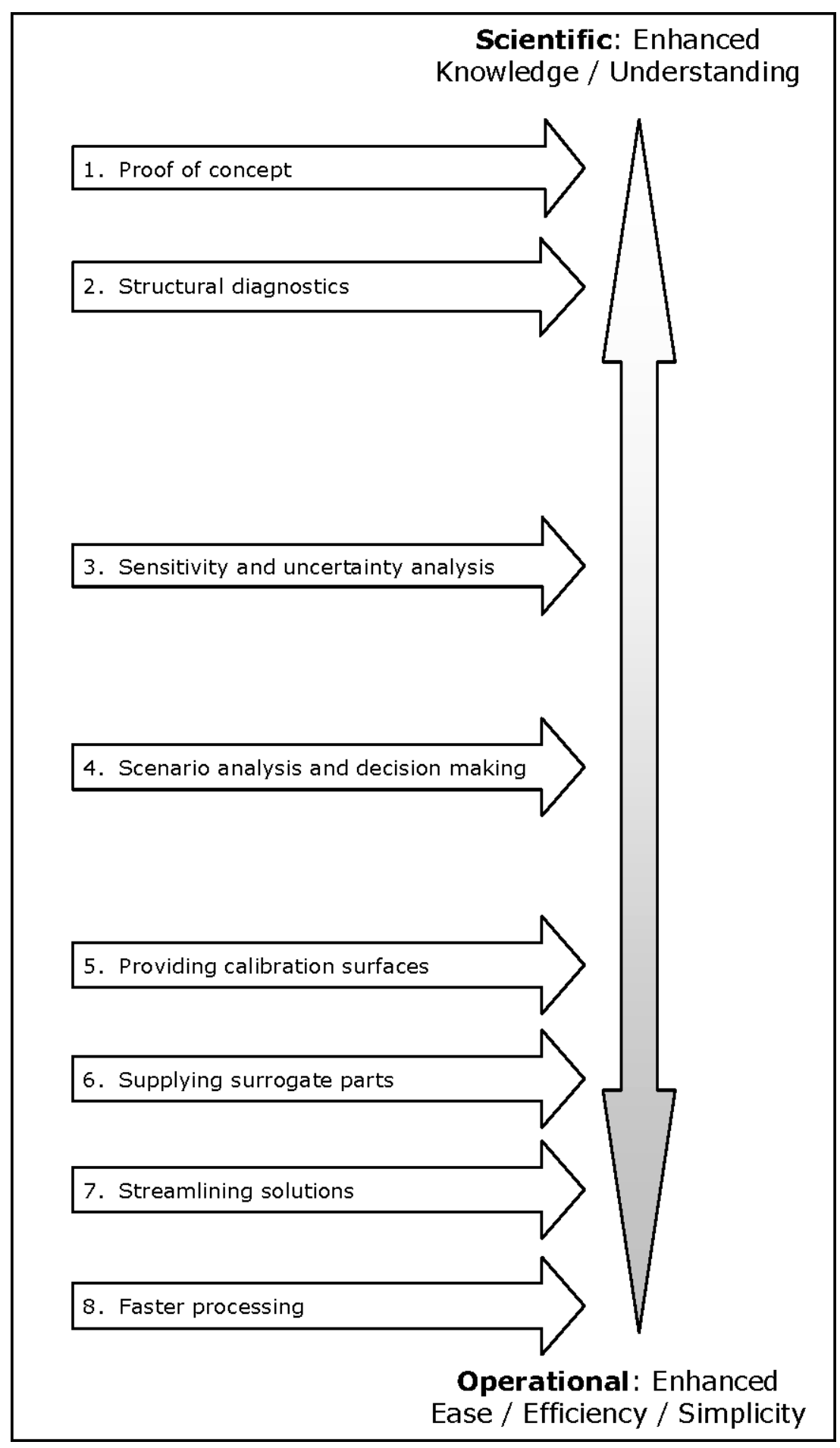

Fig 3. Schematic mapping of neuroemulation applications to the scientific-operational continuum 